\title{
Speed Control of Induction Motor using SPWM Based Multilevel Inverter and Parallel Converters
}

\author{
P. Suresh, Lokesh Anjaneya Pothana, Manoj Varma Penmetsa, Shanmukha Tejas Sunkavalli
}

\begin{abstract}
The AC motors are usually operated through a DC supply by using inverter circuits. Frequency regulation is one of the methods to regulate induction motor speed. In this paper we perform the speed control of AC motors by connecting front end $D C$-DC parallel converters for continuous operation, coupled with SPWM based multilevel inverter using sliding-mode controller algorithm for providing feedback signal and the simulation is done in MATLAB. This method reduces total harmonic distortions, improve quality of output voltage and improve motor stability.
\end{abstract}

Keywords-ZETA converter, LUO converter, Multilevel Inverter, SPWM (sinusoidal pulse width modulation), THD (Total harmonic distortions), parallel converters

\section{INTRODUCTION}

The Induction motor is used in various applications. When the load is changed in the induction motor the speed of the motor changes. To maintain the constant speed we can regulate the frequency of voltage in the multilevel inverter. To run the induction motor we need AC supply where in some circumstances we can also feed DC supply to the motor by using inverter, we can use solar power as the DC input while using the solar power as input we need to use DC-DC converter, here we are using ZETA converter as main converter, our main objective is continuous working of induction motor. If any part of converter is malfunctioned the working of induction motor is stopped so in order to avoid that we are connecting another converter parallel to provide continuous working, the type of multilevel inverter is diode clamped so backward flow of voltage is avoided and the triggering used is SPWM technique which minimizes the total harmonic distortions, the feedback signal from induction motor to the pulse is given by the sliding mode controller.

The multilevel inverter topology working and construction proposed in [1-2], the proposed article gives the information about switching frequencies, working and operation of the multilevel inverter a detail design of multilevel inverter is given in the article. The ZETA Converter topology proposed

Revised Version Manuscript Received on 10 September, 2019.

P.Suresh, Assistant Professor, Department of Electrical and Electronics Engineering, SRM Institute of Science and Technology, Kaatankulathur, Chennai, Tamil Nadu, India.

LokeshAnjaneyaPothana, UG student, Department of Electrical and Electronics Engineering, SRM Institute of Science and Technology, Kaatankulathur, Chennai, Tamil Nadu, India.

Manoj Varma PenmetsaUG student, Department of Electrical and Electronics Engineering, SRM Institute of Science and Technology, Kaatankulathur, Chennai, Tamil Nadu, India.

Shanmukha Tejas Sunkavalli, UG student, Department of Electrical and Electronics Engineering, SRM Institute of Science and Technology, Kaatankulathur, Chennai, Tamil Nadu, India. in [3], the proposed tropology is capable of providing the detailed information about the design, working, and modes of operation of ZETA converter. The LUO converter topology proposed in [4-5], the proposed tropology provides the detailed information about the design, working, and modes of operation of LUO converter. The analysis and study of induction motor is proposed in [6-7], this article provides information about induction motor efficiency, stability, losses in the motor and how to increase the efficiency. The SPWM technique proposed in [8-9], this article gives the information about sinusoidal pulse with modulation technique pulses wave forms and algorithm. This sliding mode controller working and algorithm is proposed in [9-10]. The total harmonic distortions theory is proposed in [11-12], a detailed information about harmonics, generation of harmonics in power electronic circuits and reduction of total harmonic distortions is achieved by SPWM technique .

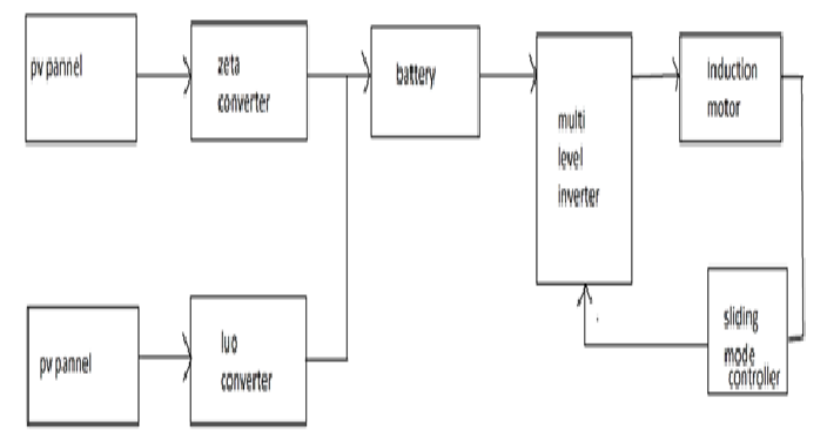

Fig.1 Block Diagramof Proposed Work 


\section{PROPOSED CIRCUIT}

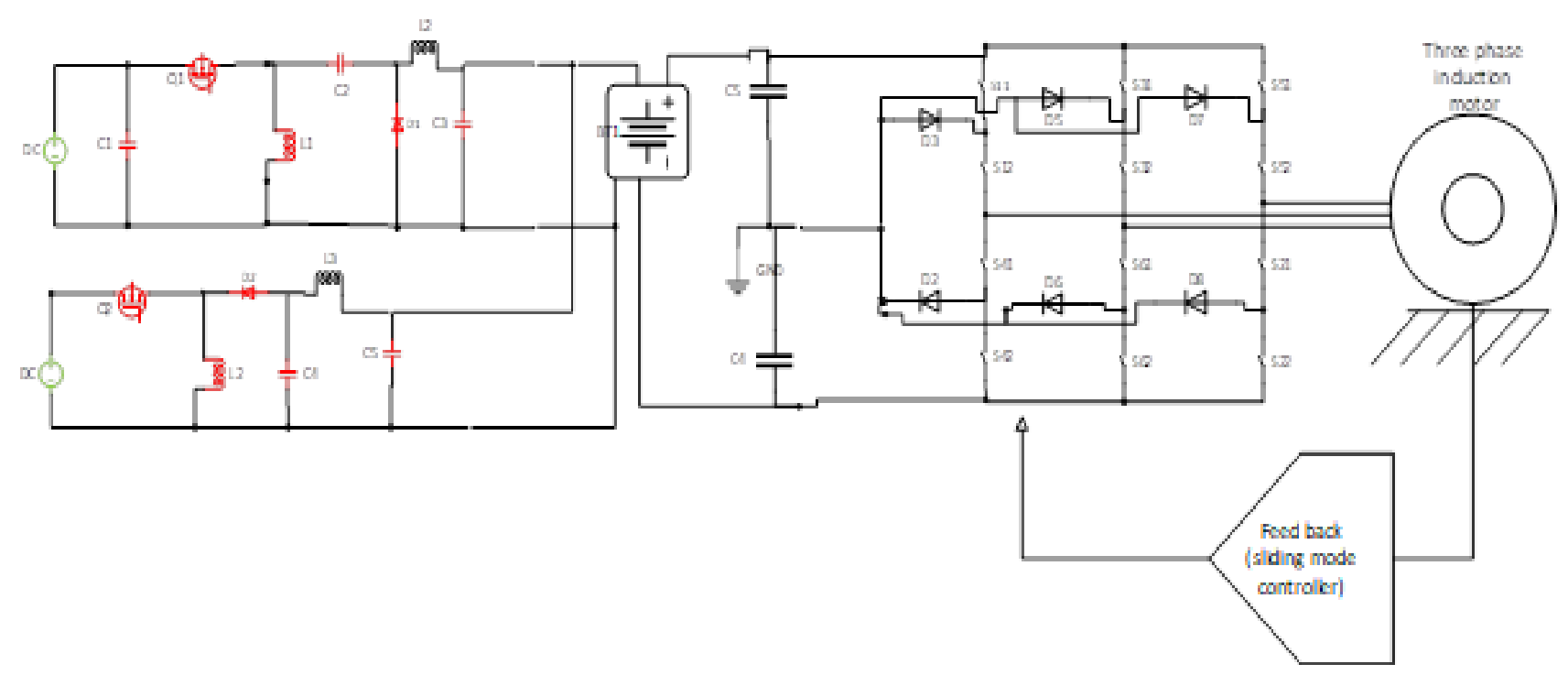

Fig.2 Circuit Diagramof Proposed Work

From this circuit our aim is to achieve continuous operation of induction motor which is of three phase. In this circuit we have connected set of parallel converters zeta converter and LUO converter to a multilevel inverter (diode clamped). It is then connected to a three phase induction motor. The feedback of induction motor is given to multilevel inverter. DC supply is given to parallel converters, which boosts the DC supply and the boosted supply is stored in the battery connected in between parallel converters and multilevel inverter. Then the stored power is given to multilevel inverter, which inverts power from DC-AC. The $\mathrm{AC}$ power is then given to induction motor according to the feedback from controller connected in between multilevel inverter and induction motor.

\section{. III. ZETA CONVERTER}

ZETA converter has a switch in series line voltage and can step-up, step-down the output voltages which make it more efficient for our usage

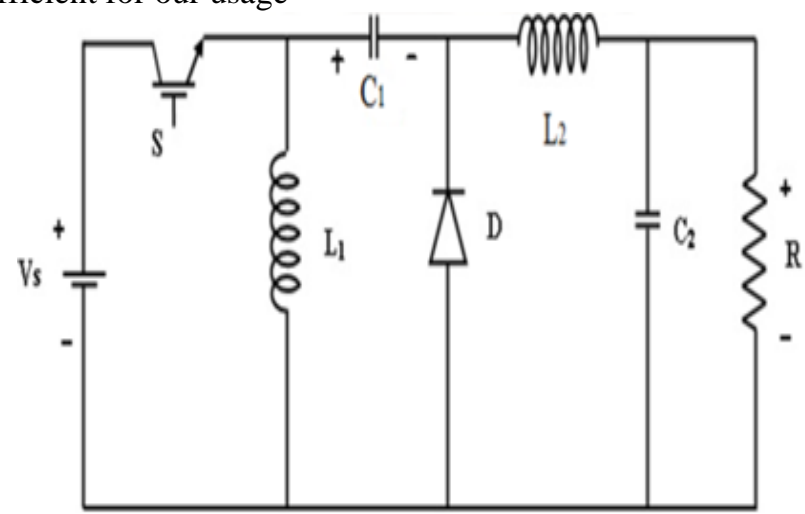

Fig.3 Basic Zeta converter circuit

A ZETA converter circuit is shown in fig.1. As several modes of operation are in existence for this converter depending on inductance value, load resistance and frequency, only continuous inductor current iL1 is analysed.

\section{A. Mode-1 Operation}

The mode 1 of operation the switch is in CLOSED and in that instant, the diode $\mathrm{D}$ is open circuited in the circuit. The circuit of mode 1 operation is shown in Fig.2. In this mode of operation, the capacitors $\mathrm{C} 1$ and $\mathrm{C} 2$ are in series with each other and the current is fed from the DC voltage source Vs through the inductor L1 and L2 and the capacitors are charged to voltage Vs which is then transferred to load $\mathrm{R}$ in the discharge mode or second mode. This mode is the charging mode since capacitors in the circuit starts charging to the value of source voltage.

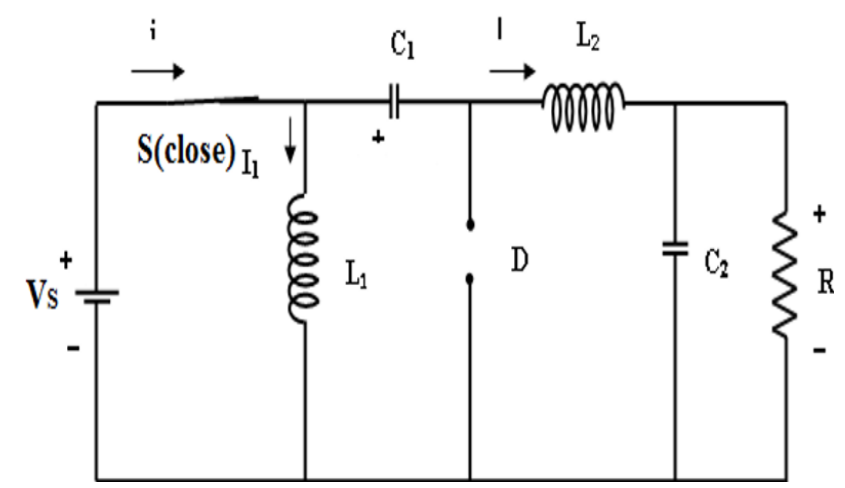

Fig.4 mode 1 operation

\section{B. Mode-2 Operation}

In the mode 2 of operation the switch is Open (off) and the diode $\mathrm{D}$ is short circuited in the circuit, the circuit shown in fig.3.In this mode of operation, the energy stored in inductor L2 is transferred or discharged to load R. Accordingly it stepup or stepdown the voltage to the load $\mathrm{R}$.

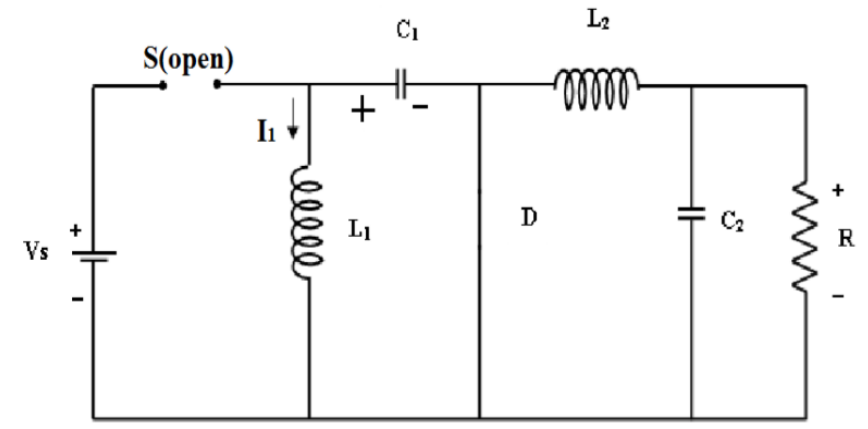

Fig. 5 mode 2 operation

Published By:

Blue Eyes Intelligence Engineering

\& Sciences Publication 


\section{DESIGN PARAMETERS OF ZETA CONVERTER}

We have taken $36 \mathrm{~V}$ from the solar panels input for zeta converter and obtained an output of 154.55 with switching frequency $1 \mathrm{MHZ}$ and range of duty cycle(D) for the modes of operation of zeta converter is

$$
\begin{aligned}
\text { Dmax } & =\frac{\text { Vout }}{\text { Vout }+ \text { Vin_min }} \\
\text { Dmin } & =\frac{\text { Vout }}{\text { Vout }+ \text { Vin_max }}
\end{aligned}
$$

Vout is output voltage and Vin is input voltage

$$
\mathrm{L} 1=\mathrm{L} 2=0.5 \times \frac{\text { Vin_min } \times D \max }{\Delta I L(p p) \times F s w}
$$

$\Delta \mathrm{IL}(\mathrm{pp})$ is Inductor peak to peak ripple current

$$
\text { Cout } \geq \frac{\Delta I L 2(P P)}{8 \times \operatorname{Cout}(p p) \times F s w}
$$

$\Delta$ VCout(pp) is output peak to peak ripple voltage that is along ouput capacitor

We can get values of input capacitor from the following equation

$$
\begin{gathered}
\text { Cin }=\frac{\text { Iout } \times \text { Dmax }}{\Delta V \operatorname{Cin}(p p) \times F s w} \\
\text { Ccouple_min }=\frac{\text { Iout } \times \text { Dmax }}{\Delta V \operatorname{Cin}(p p) \times F s w} \\
\text { Ccouple_min }=\frac{\text { Iout } \times \text { Dmax }}{\Delta V \operatorname{Cin}(p p) \times F s w}
\end{gathered}
$$

Table.1 Zeta Converter Parameters

\begin{tabular}{|l|l|}
\hline Parameters & values \\
\hline Duty cycle (D & $60-67 \%$ \\
\hline Coupling Inductors (L1, L2) & $30 \mathrm{mH}$ \\
\hline Coupled Capacitor(C_COUP) & $3 \mathrm{nF}$ \\
\hline I/P Capacitor (Cin) & $10 \mathrm{nF}$ \\
\hline O/P Capacitor (Cout) & $30 \mu \mathrm{F}$ \\
\hline Vin & $150 \mathrm{v}$ \\
\hline Vo & $650 \mathrm{v}$ \\
\hline
\end{tabular}

\section{LUO CONVERTER}

As shown in the figure, Luo Converter also has a series switch with the line voltage that can increase the voltage. It is subjected to two operating modes. The switch is in figure S2, the freewheeling diode is $\mathrm{D}$, the inductors act as passive energy storage elements (L1, L2). C1, C2 are capacitors. R acts as a resistance to load. Based on switch S2's ON and OFF conditions, its operation is split into two modes.

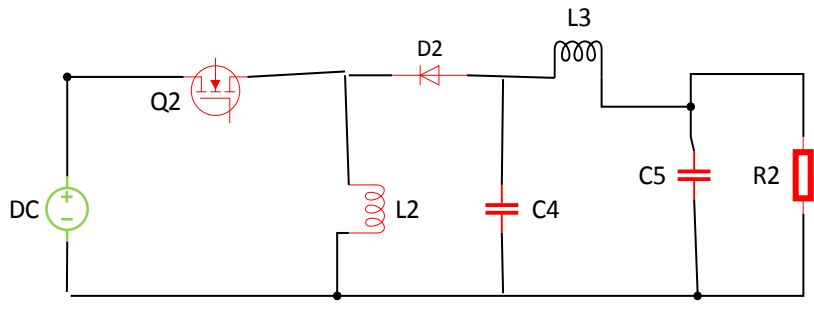

Fig.6 LUO converter

\section{A. Mode-1 Operation}

The switch is in ON condition in mode-1. The supply voltage Vs charges the inductor L2, the supply voltage C4 charges the inductor L2. Capacitor C5 provides the load with voltage.

\section{B. Mode-2 Operation}

The switch is in OFF condition in Mode-2 operation, the current from the source becomes zero. The current iL1 flows through the $\mathrm{D}$ free wheel diode and charges the $\mathrm{C} 4$ capacitor. iL2 flows to load through C5, the free wheeling diode D remains constant.

\section{DESIGN PARAMETERS OF LUO CONVERTER}

The current in inductor iL2,

Duty Ratio,

$$
\text { iL3 }=\frac{1-a}{a} i L 2
$$

$$
\mathrm{A}=\frac{T O N}{T} * 100
$$

Voltage at Output end,

$$
\mathrm{Vo}=\frac{A}{1-A} V i
$$

Across the capacitor $\mathrm{C} 1$ - avg. voltage,

$$
\mathrm{Vc} 1=\frac{A}{1-A} V i
$$

Inductor current $\Delta \mathrm{iL1}$-peak to peak,

$$
\Delta \mathrm{iL} 1=\frac{A T V i}{L 1}
$$

Inductor L1,

$$
\mathrm{L} 1=\frac{A T V i}{\Delta i L 1}
$$

inductor current $\Delta \mathrm{iL} 2$-peak to peak,

$$
\triangle \mathrm{iL} 2=\frac{A T V i}{L 2}
$$

Inductor L2,

$$
\mathrm{L} 2=\frac{A T V i}{\Delta i L 2}
$$

The charge on condenser C1 increases by iL2 during the OFF period and decreases by iL1 during ON condition. The change of charge must be equal to ripple voltage (peak to peak) across $\mathrm{C} 4$.

C1 value,

$$
\triangle \mathrm{VC} 1=\frac{1-a}{C 1} T L 1
$$

$$
\mathrm{C} 1=\frac{1-a}{\triangle V C 1} T L 1
$$

Table.1 Luo Converter Parameters

\begin{tabular}{|l|l|}
\hline Parameters & values \\
\hline Duty cycle (D) & $60-67 \%$ \\
\hline Coupling Inductors (L3) & $1.78 \mathrm{mH}$ \\
\hline Capacitor(C4) & $0.4 \mu \mathrm{F}$ \\
\hline O/P Capacitor (C5) & $2.2 \mathrm{mF}$ \\
\hline Input voltage & $150 \mathrm{v}$ \\
\hline Output voltage & $650 \mathrm{v}$ \\
\hline
\end{tabular}

\section{THREE PHASE MULTILEVEL INVERTER}

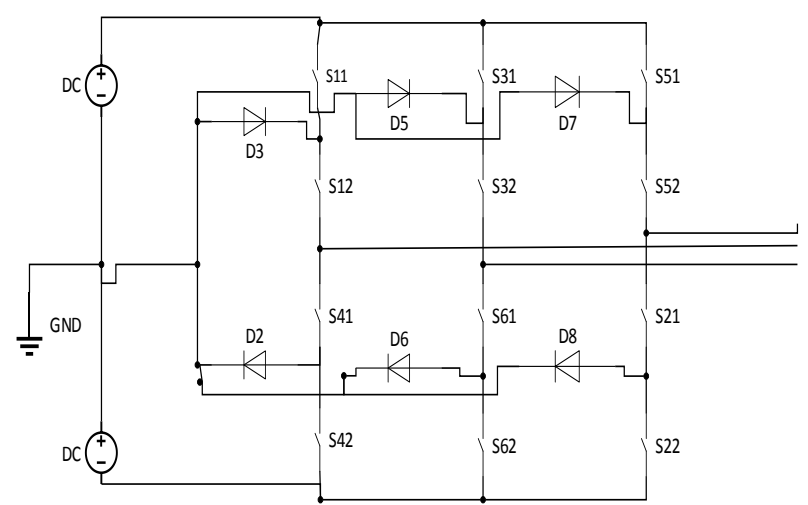

Fig.7 Multilevel inverter (Diode Clamped)

Published By: 
The multi-level inverter for three phases converts DC signal into AC signal. The type of multilevel inverter that is used in this circuit is diode clamped. This inverter is made up of two pairs of switches and diodes providing a phase signal. Once again, two capacitors $(\mathrm{C} 1, \mathrm{C} 2)$ divided each of three phases of the common DC bus shares into five levels.

The voltage at each switch is limited to Vdc by diodes Dc1, Dc2. The total voltage of the dc connection is supposed to be $\mathrm{Vdc}$ and the midpoint is adjusted at half the voltage of the dc connection, the voltage is $\mathrm{Vdc} / 2(\mathrm{Vc} 1=\mathrm{Vc} 2=\mathrm{Vdc} / 2)$ across each condenser. There are three different possible switching states in a three-level diode clamped inverter that apply the voltage of the stair case to the DC connection capasitors output voltage. For a three-level inverter, a set of two switches is on at any given time, and a set of four switches is on at any given time in a five-level inverter, and so on. The Figure 7. Table 3 summarizes the five-level inverter's switching states.Figure 7 The topology of the inverter diode-clamped -five-level. The Vab line voltage is a phase leg voltage $a$ and $b$.This means that a Nlevel diode-clamped inverter has an $\mathrm{N}$-level output phase voltage and a level output line voltage $(2 \mathrm{~N}-1)$. In general, for a $\mathrm{N}$-level diode inverter clamped at a steady state, $\mathrm{Vdc} /(\mathrm{N}-1)$ is the voltage across each capacitor. Even though only one voltage level is blocked for each active switching device. In general, clamped $\mathrm{N}$-level diode inverters require $2(\mathrm{~N}-1)$ switching devices for each leg, $(\mathrm{N}-1) *(\mathrm{~N}-2)$ clamping diodes, and $(\mathrm{N}-1) \mathrm{dc}$ connection capacitors. By increasing the number of voltage waveform becomes closer to the sinusoidal waveform. However, in high-level inverters, condenser balancing of voltage is a mojor issue. If $\mathrm{N}$ is high enough, there will be an increase in the number of diodes and switching devices and the system can not be implemented. When the inverter runs under modulation of pulse width (PWM), the major design challenge is the diode reverse recovery of these clamping diodes.

Table.3 switching modes of inverter

\begin{tabular}{|c|c|c|}
\hline Switch status & State & $\begin{array}{c}\text { Output } \\
\text { voltage }\end{array}$ \\
\hline $\begin{array}{c}\mathrm{Sa}_{1}=\text { on, } \mathrm{Sa}_{2}=\text { on } \\
\mathrm{Sa}_{3}=\text { off, } \mathrm{S}_{\mathrm{a} 4}=\text { off }\end{array}$ & Mode 1 & $\mathrm{Vao}=+\mathrm{Vdc} / 2$ \\
\hline $\mathrm{Sa}_{2}=$ on, $\mathrm{Sa}_{3}=$ on & Mode 2 & $\mathrm{Vao}=0$ \\
$\mathrm{Sa}_{1}=$ off, $\mathrm{S}_{\mathrm{a} 4}=$ off & & \\
\hline $\mathrm{Sa}_{3}=$ on, $\mathrm{S} 4=$ on & Mode & $\mathrm{Vao}=-\mathrm{Vdc} / 2$ \\
$\mathrm{Sa}_{1}=$ off, $\mathrm{Sa}_{2}=$ off & 3 & \\
\hline
\end{tabular}

\section{THREE PHASE INDUCTION MOTOR}

An electric motor is an elctro mechanical device that transforms electrical energy into mechanical energy. With 3-phase AC, the most common motor is a 3-phase induction motor, as this type of motor requires no starting device they are self starting inductive motors. For a better understanding we need to know the three-phase principle of motor induction, the essential building element of the motor. The stator consists of a 120 degrees electrical angle overlapping circuit for a 5-level diode-clamped inverter is shown in levels, the output voltage quality is improved and the voltage

winding offset. The stator is connected to a 3-phase AC source, it generates a synchronous rotating magnetic field. As the rotor winding is shut down by an external resistance or the end ring directly and cuts the rotating magnetic field, the emf is induced and current flows through the conductor of rotor as a consequence. The reason for the current generation here lies in the relative speed between thestatic rotor driver and rotating flux, and the rotor rotates in the same direction so that the cause, i.e. the relative speed, can be reduction, according to the Lenz's law. It can therefore observed that the speed of the rotor must not approach the synchronous rate of the stator, based on the operating principle of the three-phase inductive motor. There would be no such relative speed if the speeds were equal, so the emf in the rotor would not be induced and no flow current would be generated, which would cause no torque.Thus, the synchronous speed can not be reached. The slip is known as the difference between the stator (synchronous velocity) and the rotor speed. A magnetic field rotation in an induction motor has the benefit of not requiring electronic connections to the rotor.

\section{SPWM TECHNIQUE IN MULTILEVEL INVERTER}

SPWM technique is one of the most popular modulation techniques used in the use of power switching converters in a wide range of industrial applications.. The most pefered technique for high power applications is form of modulation for high-power application is the low carrier frequency ratio (fc) to modulation frequency (fm). However, a system based on DSP / Microcontroller uses regular symmetric sampling or resampling. These techniques of sampling either introduce the delay or require a particular processor. This paper contains a simple SPWM technique mathematical model. On the Artificial Neural Network (ANN), this technique is further extended and implemented. The digital implementation of the SPWM technique is based on traditional carriers and the SPWM technique of reference sine waveform. The only difference is that the SPWM digital technique uses a sine table of sine waveform values which are sampled at a particular frequency.As a result, digital SPWM's reference waveform represents a sample and holds the sine waveform waveform.The sine waveform sampling takes place in two variants: symmetric sampling, asymmetric sampling. At the only positive peak of the carrier waveform, the reference sine waveform is sampled in symmetrical sampling and the sample is kept constant throughout the period of the carrier. This distorts the modulation of the signal from the phase shift between signal modulation and the basic component of the output voltage. The frequency of sampling is equal to the frequency of the carrier. The shift of the phase is $\pi / \mathrm{m}$.

$$
\mathrm{Mf}=\frac{f c}{f m}
$$

The reference signal is sampled at both positive and negative carrier frequency peak in asymmetric sampling and kept constant for half the carrier period. Here the frequency of sampling is twice the frequency of the carrier. 
Asymmetric sampling is the preferred method, as each switching edge is the result of the new sample and provides better performance. The shift in the phase is $\pi / 2 \mathrm{mf}$. The sample PWM technique is analog signal that naturally samples the signal in the input at the instant of the switching edge by the carrier triangle waveform. The sampled PWM reacts instantly as the input signal changes and does not attenuate the synthesized waveform or distort it. However, the rate of $\mathrm{f} 1$ is more to that of triangle carrier as the ratiof $1 / \mathrm{fc}$ increases for a given modulation depth $\mathrm{M}$, generating an extra pulse. If it is possible to tolerate these additional pulses, it will preserve the integrity of the synthesized waveform. The sample PWM modulator naturally offers low delay, distortion and wide bandwidth for a low-switch frequency converter. Many implementations of multilevel converters published in the literature use natural sampled carrier-based diagrams to demonstrate their technique of modulation. Nevertheless, as analog technique is implemented. An analog signal is not used itself to multi-level implementation of high-power. All desirable analog and digital SPWM features require a digital implementation of analog SPWM. Uniform PWM re-sampled is a digital implementation that addresses natural PWM's frequency and transient response. Instead of sampling at the beginning of the PWM switching period only once per switching edge, additional samples are noted in the switching period as shown in Figure 9. The latest sample determines the position of the switch edge. This achieves the desired result, but it is necessary to take into account some possibilities of multiple edges gives complexity. such as the possibilities of missed or multiple edges. Re-Sampling Ratio, $\mathrm{rsr}=\mathrm{fs} / 2 \mathrm{fc}$ measure the re-sampling rate, $\mathrm{fc}=$ carrier frequency, $\mathrm{fs}=$ Higher sampling frequency: Moderate re-sampling ratio values significantly improve the modulator's frequency response, delay, and distortion, especially for high modulation depth.

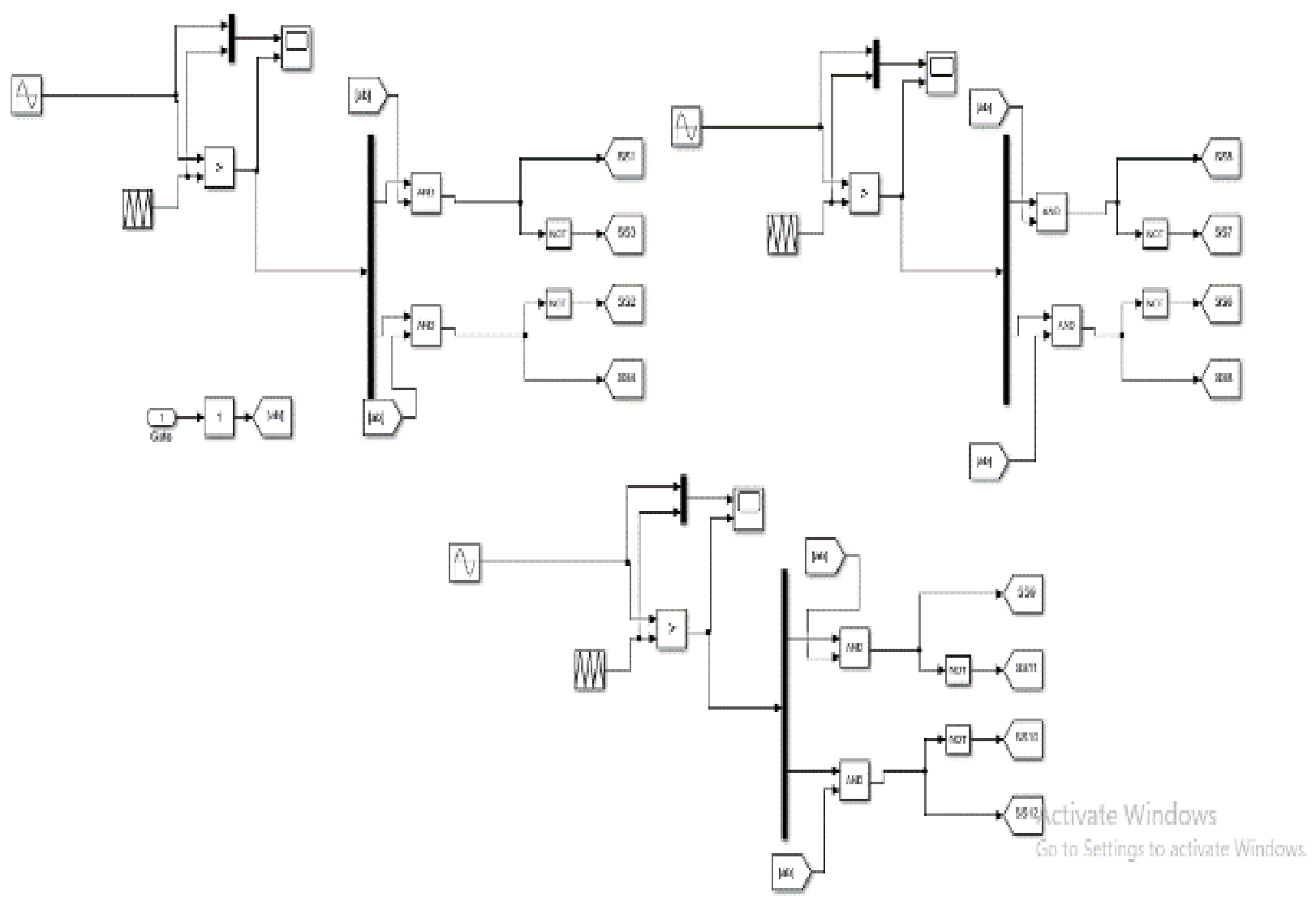

Fig.8 SPWM technique algorithm 

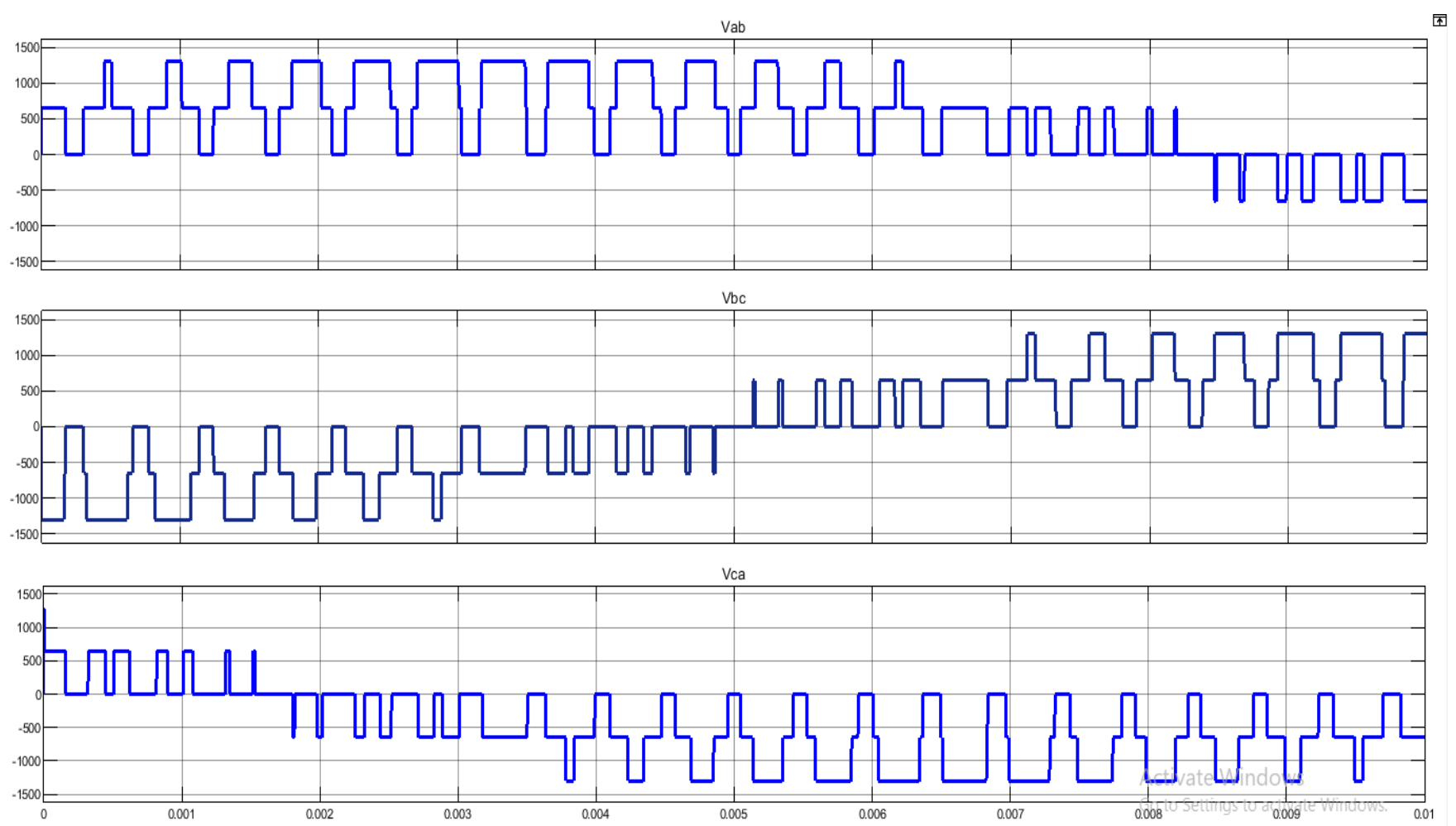

Fig.9 SPWM waveforms

\section{VIII.THD REDUCTION USING SPWM TECHNIQUE}

The excessive use of electronic power devices today leads to the more reactive power and harmonics in current and voltage in the network of the power system. The voltage of the power system network at different buses get distortions and the components connected or not operated as intended.These harmonic currents contaminate the system, which causes the problems like overheating of the transformer, voltage degradation, vibration of the rotating machine, destruction of electrical components and malfunctioning medical facilities.Several PWM techniques are available to allow VSI to switch pulses. The SPWM technique used in this design, among other techniques, as the voltage output of inverter and output frequency can be controlled directly according to the sine functions The voltage source inverter should be controlled in such a way that the voltages generated by the detection and control block are the same as the reference voltages. The PWM switching techniques are used by the voltage source inverter to have a magnitude-constant DC input voltage $(\mathrm{VDC}=\mathrm{VS})$. The inverter converts this DC input to AC output to control the magnitude and frequency.

An inverter's efficiency parameters such as switching losses and harmonic reduction to control the inverter depends mainly on the modulation strategies. Sinusoidal pulse width modulation (SPWM) is widely used in power electronics to digitize the power, allowing the on and off of the power switches to generate a sequence of voltage pulses. VIn general, the three-phase inverter uses three sinusoidal waves. The sinusoidal waves are referred to as the reference signals and differ from each other in 1200 phases. Based on the required output frequency of the inverter, the frequency of these sinusoidal waves is selected. The triangular carrier wave is generally a high frequency wave (in a few $\mathrm{KHz}$ ).

By comparing the sinusoidal waves to the triangular wave the switching signals are generated. When the sine voltage is greater than the triangular voltage, a pulse is given by the comparator and the respective inverter switches are triggered by this pulse. The switches of any leg in the inverter can not be switched off simultaneously to avoid undefined switching states and undefined AC output line voltages in the VSI.

If the control block and detection generated reference voltage is given to inverter as modulating waveforms, the fundamental component of the inverter output will be the same as the control block and detection generated reference voltages. This advantage of SPWM technique (simplifying our design) justifies the selecting spwm technique as switching strategy of inverter. It also have advantages such as 1) Frequency of switching is constant ; 2)High frequency side drags the switching hormonics. By choosing a very high modulation frequency, reduces the filter requirement. The switches can be switched $\mathrm{ON}$ and OFF as required in the inverter. When switching ON and OFF once in each cycle, the top switch is switched on in the simplest approach, resulting in a square waveform. However, less harmonics can be obtained if switched on several times in a cycle.

By comparing the reference waveform to triangular waform's highest frequency the required output voltage is generated. Dpends on the voltage signal, if it is more than or less than the carrier waveform, the negative or positive bus voltage is applied in the output. The average voltage applied to the load during this The resulting square waveform contains in its low frequency components a replica of the desired waveform with the higher frequency components at 
frequencies close to the carrier frequency. The root mean square value of the ac voltage waveform is still the same as the dc bus voltage, so the entire harmonic distortion is not affected by the PWM process. The harmonic components are simply moved through inductances into the high frequency range and filtered automatically in the ac system.

The ratio $\mathrm{M}=\mathrm{Am} / \mathrm{Ac}$ is called the modulation index when the modulating signal is a sinusoidal signal AM and the amplitude of the triangular carrier is Ac. Modulation index control controls the amplitude of the output voltage applied. Due to the presence of inductive elements with a sufficiently higher carrier frequency, the higher frequency utilizers do not propagate significantly in the ac network (or load). However, a higher frequency of carrier results in a higher number of switches per cycle, leading to a higher power loss. Switching frequencies ranging from 2 to $15 \mathrm{kHz}$ are generally considered suitable for power systems applications. Where Vtri is the carrier wave signal, Vcontrol is the control signal, $\mathrm{VA} 0, \mathrm{VB} 0, \mathrm{VCO}$ is the inverter output line to neutral voltages, $\mathrm{VAB}, \mathrm{VBC}, \mathrm{VCA}=$ line to line output voltages of inverter, Vtri= fs frequency, Vcontrol frequency $\mathrm{f} 1$, fs= PWM frequency and $\mathrm{fl}=$ basic frequency.

\section{SLIDING MODE CONTROLLER}

Sliding Mode Controller is a robust, nonlinear discontinuous control that changes the dynamics of a nonlinear system by applying a variable control signal to the structure. This control signal forces the system to reach a predefined surface (called the sliding surface) and subsequently remain on. When confined to the surface, the dynamic behavior of the system is called sliding mode. The beauty of this SMC is model parameters need not be accurately known only in order to know their boundaries and the controlled system is insensitive to the system parameter variation and is therefore highly robust.Design involves two steps: 1) Selecting the stable hyper plane(s) in the state / error space to restrict the motion, called the Sliding Surface. 2) Synthesis of a control law that attracts and remains on any arbitrary initial condition to Sliding Surface. A trajectory that begins with an initial non-zero condition evolves in two ways:

1) Achievement mode in which the sliding surface is reached 2) Sliding mode in which the trajectory on the sliding surface remains. That's when the system is insensitive to the plant's parameters. Attractive surface (sliding surface): it is converged outside of the surface by trajectories. Once on the surface, trajectories remain on it. Corrective Control: offset the deviations in the sliding surface to reach the sliding surface. Equivalent Control: makes the sliding surface derivative equal to zero to stay on the sliding surface.

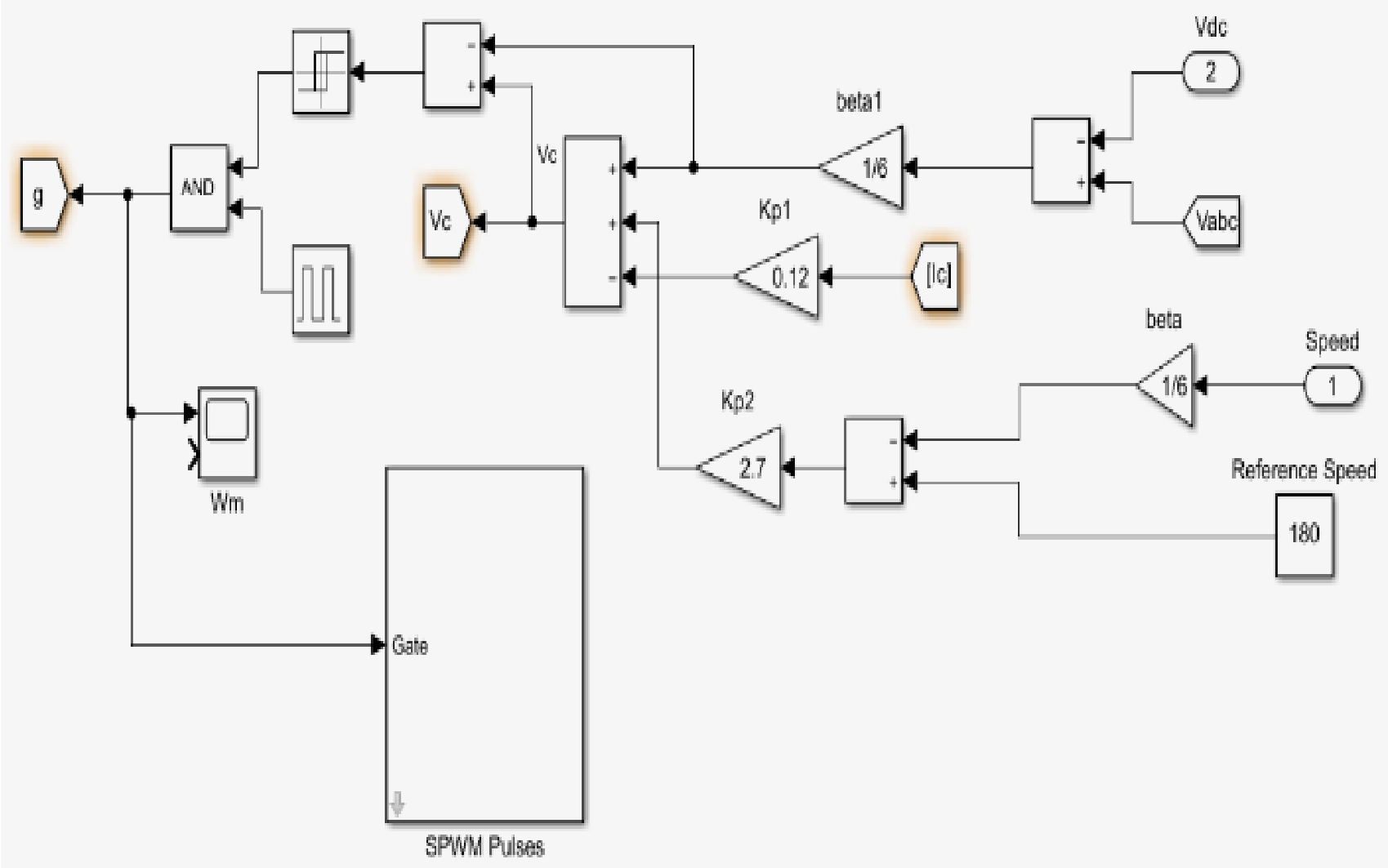

Fig.10 Sliding mode controller algorithm 


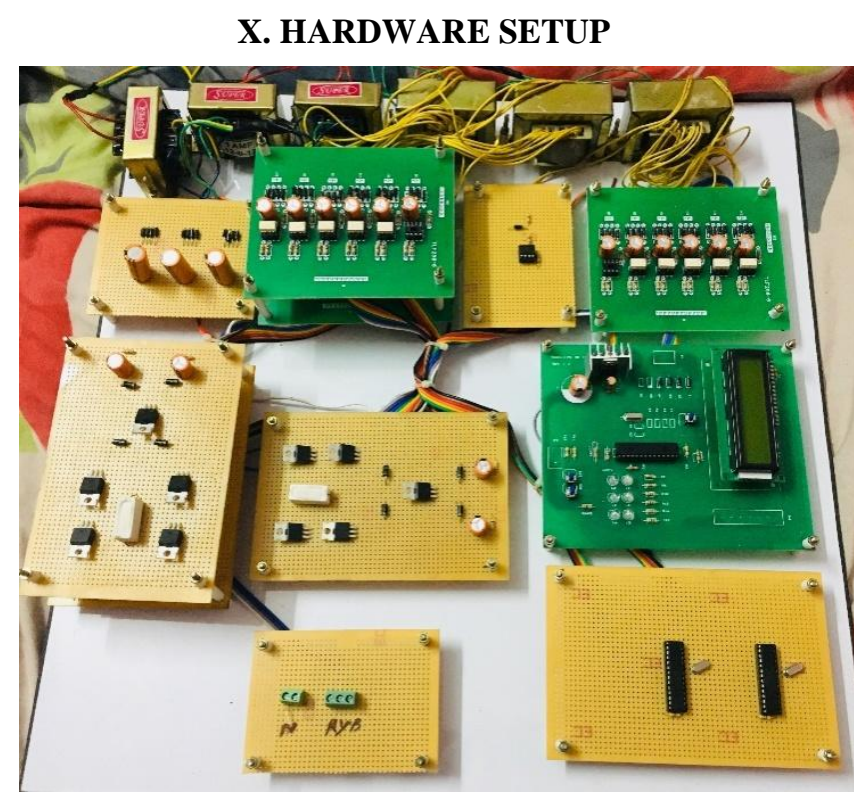

Fig.11 Hardware setup

XI. OUTPUT WAVEFORMS\&RESULTS

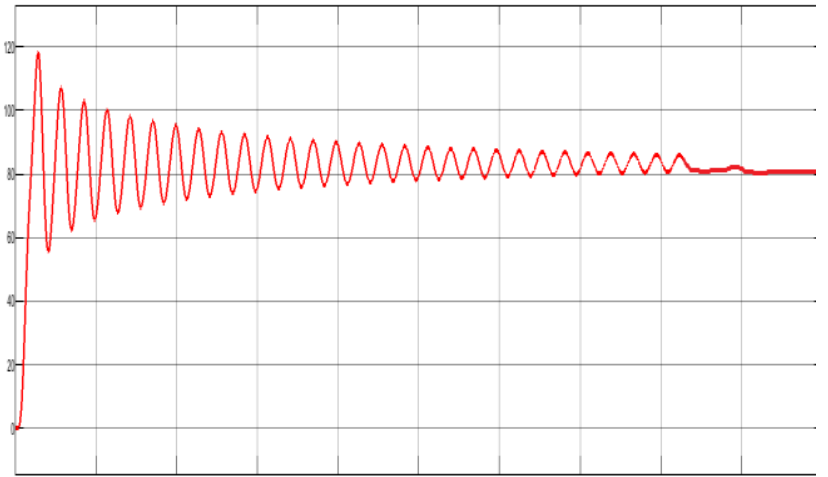

Fig.12 Speed of induction motor( in RPS)

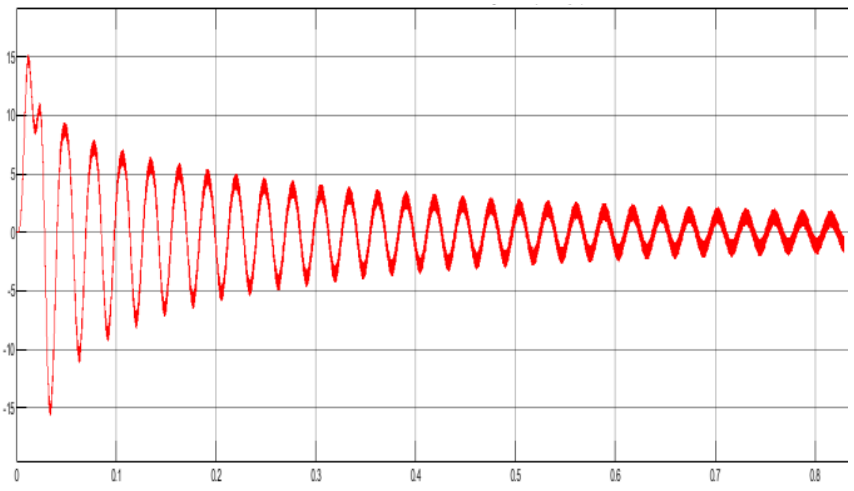

Fig.13 Torque of induction motor
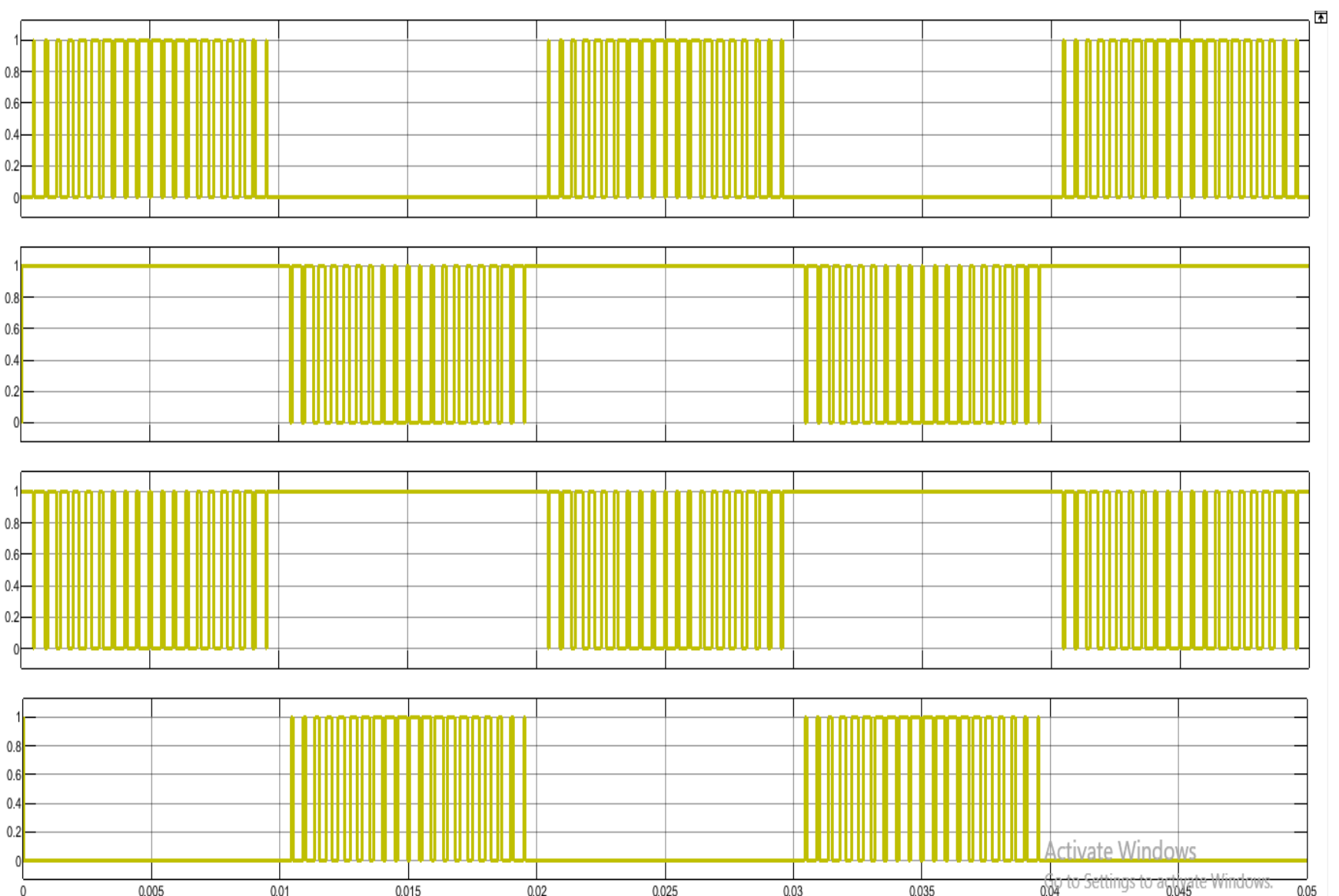

Fig..14 Gate pulse for switches S11, S12, S41, S42

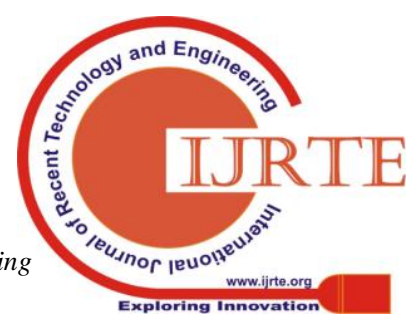



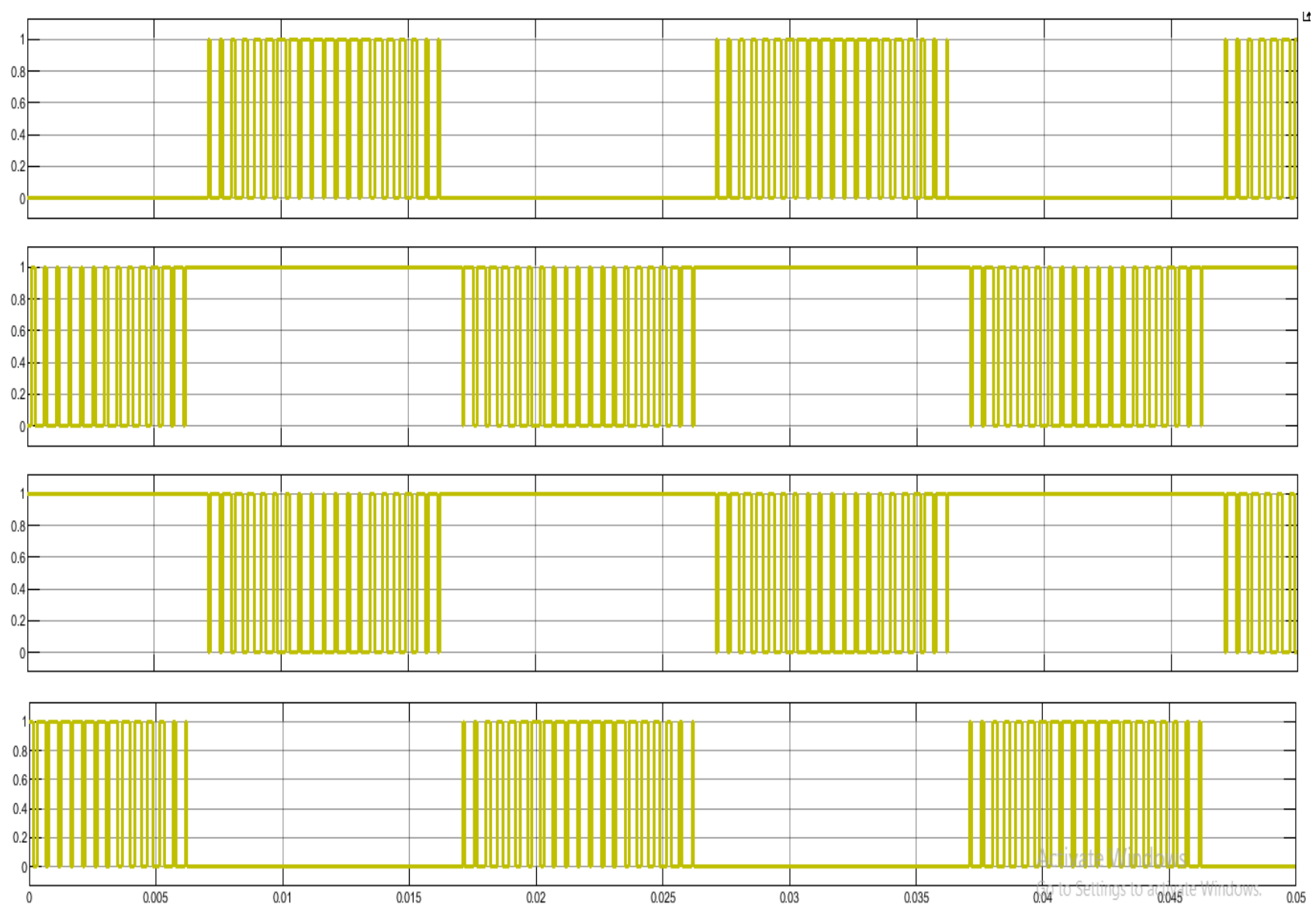

Fig.15 Gate pulse for switches S31, S32, S61, S62
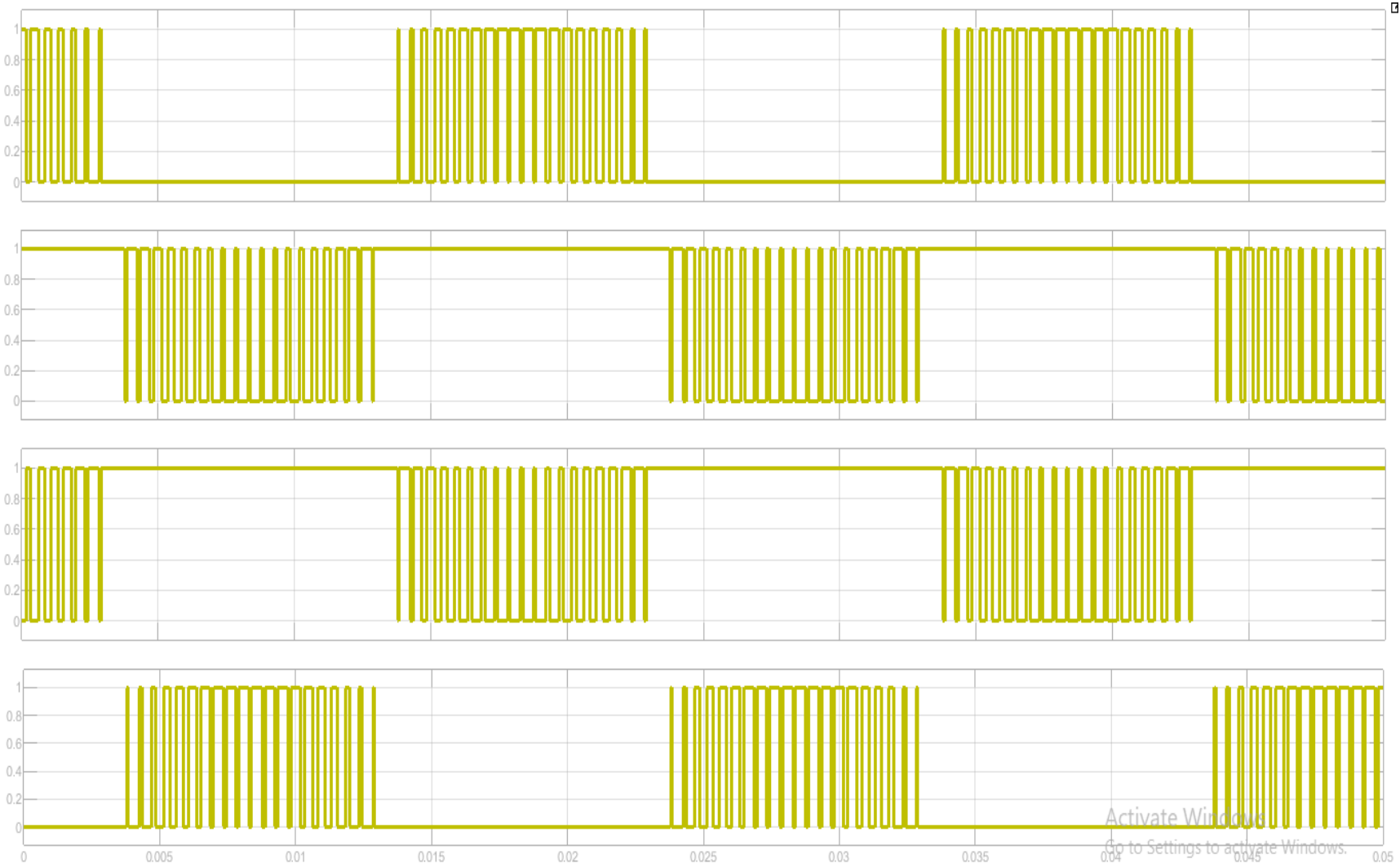

Fig.16 Gate pulse for switches S51, S52, S41, S42

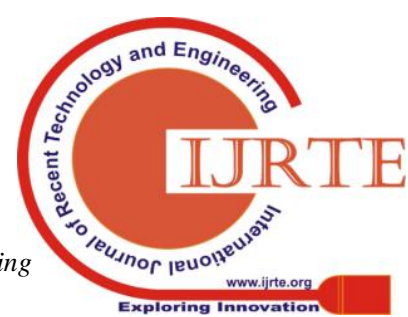



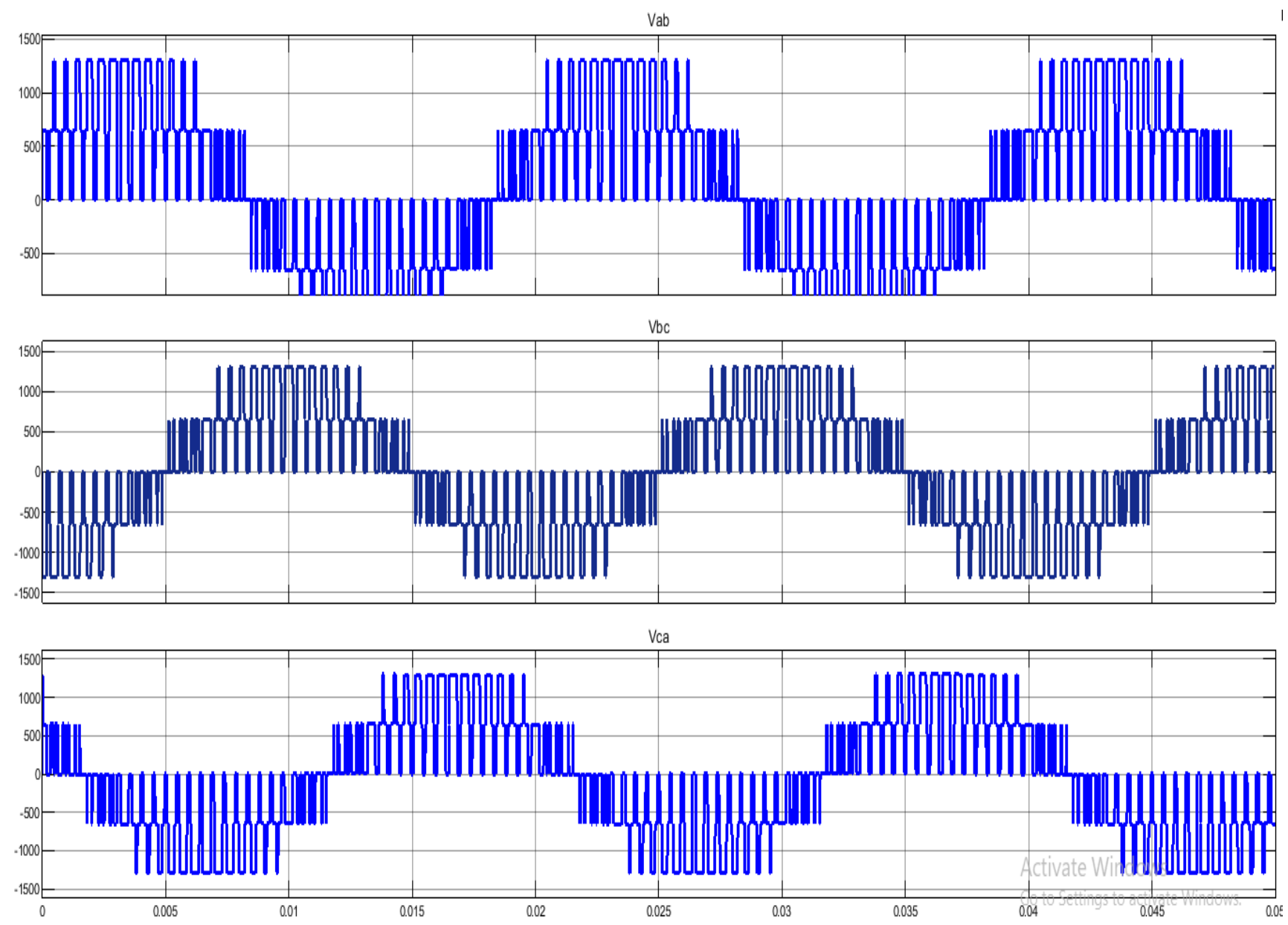

Fig.17 Voltage waveform of multilevel inverter
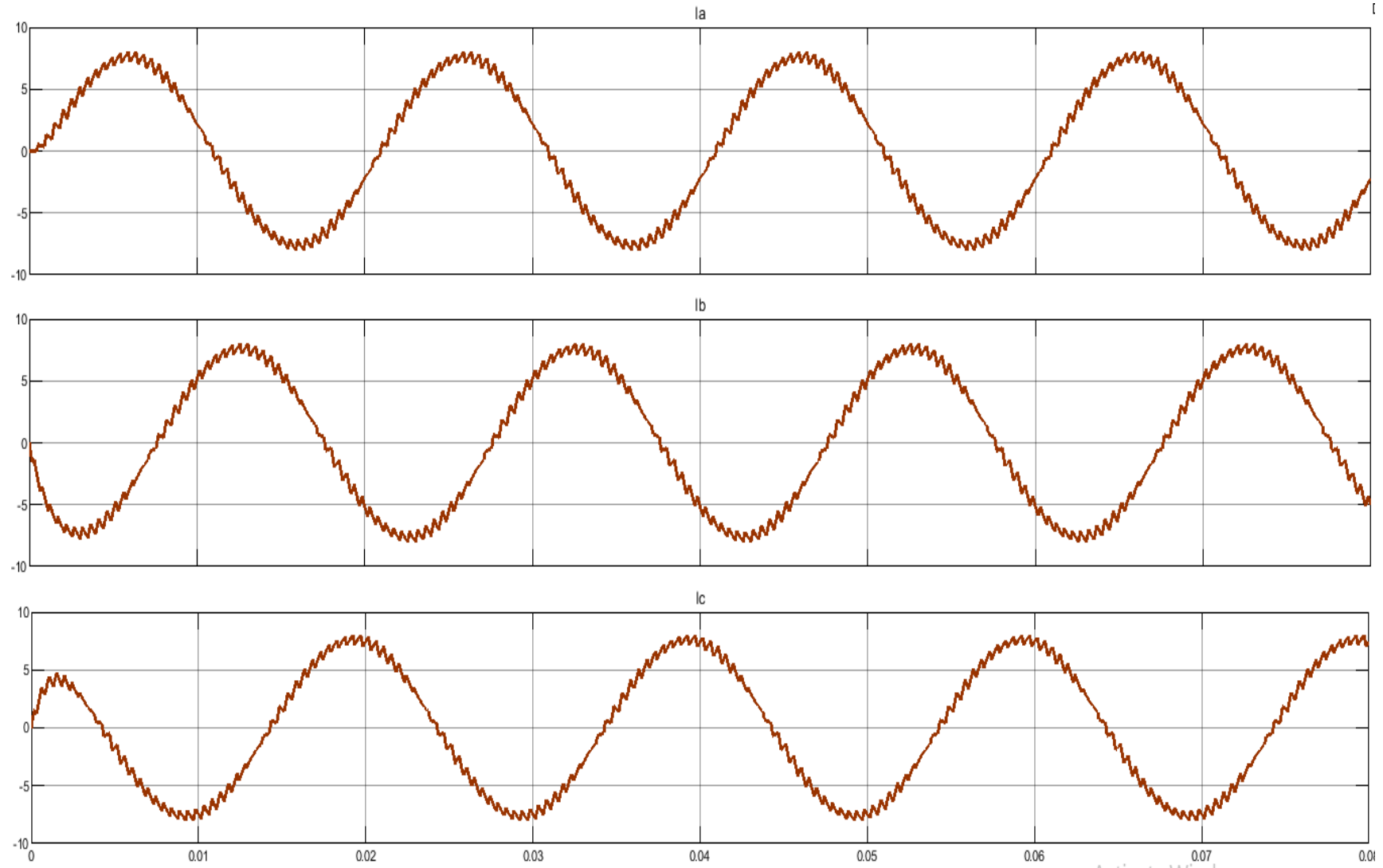

Fig.18 Current waveform of multilevel inverter

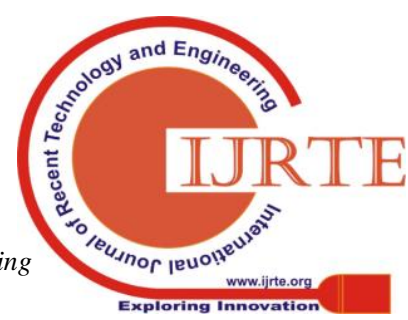




\section{XII.CONCLUSION}

For stable operation of three phase induction motor, we have used parallel converters coupled with diode clamped multilevel inverter, which is controlled by SPWM technique. SPWM technique is widely popular for its industrial applications. With the use of this SPWM technique, we have successfully reduced the total harmonic distortions and the feedback of induction motor is given to the multilevel inverter via sliding mode controller. We can also achieve uninterruptable operation of induction motor with the help of parallel converters as if one converter fails to operate, another standby converter is enough to run the induction motor.

\section{REFERENCES}

1 "A five-level singlephasegrid-connected converter for renewable distributed systems," IEEE trans Ind. electron, Vol.60, No.3,Mar. 2013.

2 "Multilevel inverters: A surveyof topologies, controls, applications," IEEE trans ind. electron, Vol. 49,No. 4, Aug. 2002.

3 "Dynamic Modeling and Control of a Zeta Converter," 2008 (ISCIT 2008), Oct. 2008.

4 "Modified positive output luo converters" proc. IEEE Intl. conf. Jul. 1999.

5 "Parallel operation of modular single-phase transformerless grid-tied PV inverters with common DC bus and AC bus" IEEE journ. Emer. \&amp; Sel. Dec 2015.

6 "General synergetic control strategies for arbitrary number of paralleled buck converters feeding constant power load: implementation of dynamic current sharing" IEEE ISIE vol. 1 pp. 257-261 2006.

7 "A synergetic control approach for induction motor speed control" industrial electronics society vol. 1 pp. 883-887 2004.

8 "Development of a Single Phase SPWM Microcontroller-Based Inverter PEC (p. 437) IEEE.

9 "Application of Sinusoidal Pulse Width Modulation Algorithm in the Grid-Connected Photovoltaic System " (ICM) 2011 international conference on Vol. 2 no. Sept. 2011.

10 "A survey on sliding mode control strategies for induction motors" annual reviews in control pp. 289-3

11 "Linear and Sliding-Mode Control Design for Matrix Converter-Based Unified Power Flow Controllers" IEEE Transactions vol. 29 .July 2014. 07 December 2013.

12 "A simple approach to current THD prediction for small-scale grid-connected inverters" Appl. power electron. Conf. and Expo. (APEC) 2015 IEEE.

13 "Calculating the Formula of Line-Voltage THD in multilevel inverter with unequal DC Sources" IEEE trans. ind. Electron.Aug. 2011. 